\title{
ISSUES IN AGING IN INDIVIDUALS WITH LIFE LONG DISABILITIES
}

\author{
Connolly BH \\ Department of Physical Therapy, Health Science Center, University of Tennessee, Memphis, Tennessee, USA \\ Correspondence to: Department of Physical Therapy, Health Science Center, University of Tennessee, 930 Madison \\ Avenue, Suite 646, Memphis, Tennessee 38163, USA
}

Received: 06/03/2005 - Accepted: 07/04/2006

\begin{abstract}
Introduction: The major research data and findings related to aging among persons with developmental disabilities are discussed. Topics addressed include prevalence and mortality rates, as well as the effects of aging on the sensory systems, the neuromusculoskeletal system and the cardiopulmonary system. The discussion also focuses on the clinical implications of these changes among aging individuals with developmental disabilities. Conclusion: Although the individual needs of persons with developmental disabilities vary greatly, knowledge of the effects of aging on this group of individuals can facilitate more effective healthcare by physical therapists for all adults with developmental disabilities.
\end{abstract}

Key words: aging, developmental disabilities, sensory system, neuromusculoskeletal system, cardiopulmonary system.

\section{RESUMO}

\section{Tópicos Sobre o Envelhecimento em Indivíduos com Incapacidades Prévias}

Introdução: Os dados de pesquisa mais importantes e seus resultados relacionados ao envelhecimento de pessoas com incapacidades prévias são aqui discutidos. Os tópicos abordados incluem a prevalência e os índices de mortalidade, bem como os efeitos do envelhecimento sobre os sistemas sensitivos, músculo-esquelético e cardiopulmonar. A discussão também aborda as implicações clínicas destas mudanças no indivíduo que envelhece sendo portador de uma incapacidade prévia. Conclusão: Embora as necessidades individuais de pessoas com incapacidades variem muito, o conhecimento dos efeitos do envelhecimento neste grupo de indivíduos pode promover o uso de cuidados de saúde mais eficientes pelos fisioterapeutas que cuidam de adultos com incapacidades prévias.

Palavras-chave: envelhecimento, incapacidades prévias, sistema sensitivo, sistema neuromusculoesquelético, sistema cardiopulmonar.

\section{INTRODUCTION}

Interest in the management of individuals with lifelong disabilities is growing. The number of adults with lifelong disabilities also continues to grow due to advances in medical management and to increased life expectancies in the adult population in general ${ }^{1,2}$. According to a 1997 United States of America (USA) Bureau of the Census report, nearly 54 million citizens have an activity limitation/disability associated with a long- term physical, sensory, or cognitive condition ${ }^{3}$. This increase also has been reported in other countries (e.g. Italy, Canada, Australia, and England $)^{4-6}$. Individuals with developmental disabilities are being served in the community and are frequently living to be more than 60 years old ${ }^{7,8}$. However, services for adults with lifelong disabilities are often inadequate even in developed countries ${ }^{5,9,10}$.
In pediatric rehabilitation, the tenet that children cannot be addressed as if they were small adults has been widely embraced. However, the difficulty in transition of services for the child with developmental disabilities to services for the adult with developmental disabilities has not been fully explored or perhaps appreciated by occupational or physical therapists with pediatric experience. Additionally, therapists in adult practice settings may be presented with unique problems in the adult with developmental disabilities that they are not prepared to address. Although individual needs of persons with developmental disabilities vary greatly, knowledge of the effects of aging on this group of individuals can facilitate more effective health care by occupational therapists and physical therapists for individuals of all ages with developmental disabilities. 


\section{DEFINING THE POPULATION}

\section{Definition of Developmental Disabilities and Mental Retardation}

Developmental disability can be defined as: "a severe chronic disability of a person which: (1) is attributable to a mental or physical impairment (or a combination of impairments); (2) is manifest before age 22; (3) is likely to continue indefinitely; (4) results in substantial functional limitations in three or more of the following areas: self care, receptive and expressive language, learning, mobility, self direction, capacity for independent living or economic self sufficiency; and (5) reflects a need for a combination and sequence of special, interdisciplinary or generic care, treatment or other services which are (a) of lifelong or extended duration and are (b) individually planned and coordinated" ${ }^{11}$.

Mental retardation refers to substantial limitations in functioning of an individual. It is characterized by significantly sub-average intellectual functioning, existing concurrently with related limitations in two or more of the following applicable adaptive skill areas: communication, self-care, home living, social skills, community use, self-direction, health and safety, functional academics, leisure, and work ${ }^{12}$.

Although developmental disabilities and mental retardation have been carefully delineated, the definition of "aged" as applied to these populations is not as clear. Aging typically has been defined using a normative-statistical approach (chronological age), while others have used a biological approach related to signs and symptoms of aging. Thus, inconsistencies in the operational definitions for aging in individuals with disabilities were found by Janicki and $\operatorname{Hogg}^{13}$. In individuals with lifelong disabilities such as Down syndrome, aging may begin as early as 35 years. Research has shown that almost all adults with Down syndrome over the age of 35 years develop Alzheimer neuropathology ${ }^{14,15}$. Burt et al. found that adults with Down syndrome showed evidence of loss of previously attained adaptive skills more frequently than individuals with mental retardation, but without Down syndrome ${ }^{16}$. Additionally, Burt et al ${ }^{16}$ found that 8 of 61 adults with Down syndrome in their study had symptoms of dementia whereas none of the comparison subjects had diagnosable dementia. For adults with Down syndrome over 55 years of age, the incidence of Alzheimer's disease has been estimated at $45 \%{ }^{17}$. Evenhuis ${ }^{18}$, found an even greater percentage of individuals with Down syndrome with dementia (88\%) in his prospective study of 17 individuals followed from the time of institutionalization to death. Two studies based on postmortem examinations seem to indicate that individuals with MR (but without Down syndrome) may be at risk for Alzheimer's disease at ages roughly comparable to those of adults without $\mathrm{MR}^{19,20}$. Janicki and associates ${ }^{13 \text {, }}$ ${ }^{21}$ also documented that individuals with MR and cerebral palsy may experience effects of aging on mobility and activities of daily living (ADLs) earlier than individuals without MR. However, most researchers have selected the mid-50s as a definition of "aged" in adults with developmental disabilities based on observations of changing functional status in normative age-related activities ${ }^{22}$.

\section{Life Expectancy}

Life expectancy for all individuals with developmental disabilities has increased but is less than for the general population ${ }^{7,24-30}$. For example, the lifespan for individuals with Down syndrome has increased from 9 years of age in 1949 to approximately 55 years today ${ }^{31}$. Jacobson et al. ${ }^{32}$ found the greatest life expectancy to be in women, people who are ambulatory and/or have mild levels of mental retardation, and those who have remained in community settings. O'Brien et al. ${ }^{33}$ found a significantly higher mortality rate in individuals with developmental disabilities between 1974 - 1979 when compared to 1980 - 1985. Heart disease and cancer were found to be the most common causes of death in individuals with mild, moderate, or severe mental retardation in both these time periods. Additionally, respiratory disease was found to be the most common cause of death in individuals with profound mental retardation ${ }^{33}$. In 1999, Shavelle and Strauss ${ }^{34}$ in a study of 1,812 persons who had left institutions to move into the community found that the community death rate was $88 \%$ higher than expected for comparable persons living in institutions. They also found that relative mortality in the community seemed to be greatest among the highest functioning persons. Causes of death included diseases of circulation, cancer, pneumonia, aspiration pneumonia, choking, trauma, and cardiac arrest (in some cases due to infection). Hemming et al. ${ }^{7}$ in a study of 341 individuals in England ( born between 1930 - 1960) found that almost $85 \%$ of the cohort survived to age 50 years. Female adults survived better than male adults. In contrast the to Shavelle and Strauss ${ }^{34}$ study, fewer deaths due to injuries and accidents were found in the cohort than would have been expected in the general population.

As individuals with developmental disabilities age, they experience age-related disorders similar to individuals without developmental disabilities ${ }^{35}$. However, in addition to these disorders, a variety of secondary medical problems that may contribute to mortality have been described. Secondary medical problems identified by Buehler et al. ${ }^{36}$ in a study of 610 adults with developmental disabilities, primarily from community settings, included obesity, chronic skin problems, hygiene related problems, and early aging. ( Figure 1) Hemming et al. ${ }^{7}$ found the most common underlying causes of death to be diseases of the circulatory system, neoplasms, and disease of the digestive or nervous system.

Kapell et al. ${ }^{35}$ found that people with MR had a greater incidence of hypothyroidism and non-ischemic heart disease when compared with their age and gender matched peers 
in the general population. Anderson ${ }^{37}$, in a study of older adults with MR who lived in community settings, found that the most common chronic health problems included high blood pressure, arthritis, heart disease, and glaucoma/ cataracts. These disorders were consistent with the top three health problems noted in the general population of persons of similar ages.

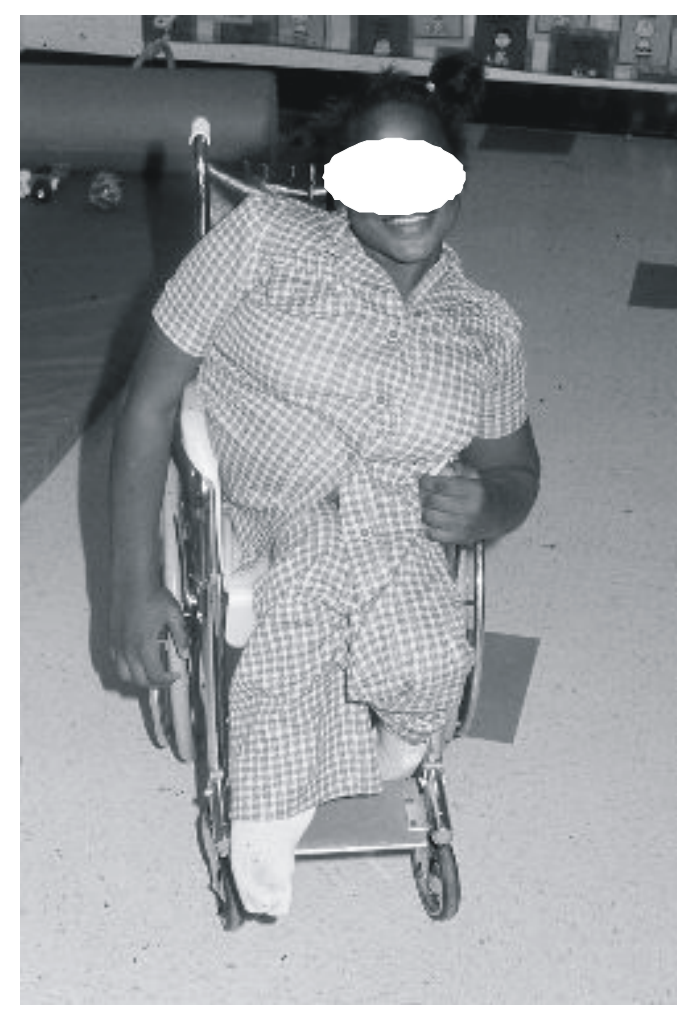

Figure 1. Obesity in individual with developmental disabilities.

\section{EFFECTS OF AGING ON THE SENSES}

Even minor functional changes of aging in areas such as vision, hearing, and vestibular functioning may cause major problems for individuals who have had lifelong developmental disabilities. An understanding of how some of the general needs of these individuals can be served by medical and community systems is essential for occupational therapists and physical therapists who serve this population.

\section{Vision}

Age- related loss in the photoreceptors and decreased function of the ganglion cells within the retina have been shown to occur in individuals ${ }^{38}$. Additionally, aging has been shown to affect the integrity of the visual fields, dark adaptation, and color vision with some loss over the entire color spectrum by the fourth decade $\mathrm{e}^{39,40}$. With aging, the pupillary responses have been noted to decrease, as well as the size of the resting pupil $^{41}$. Cohen and Lessell ${ }^{39}$ reported that with aging, con- vergence is compromised, ptosis is seen, and a symmetric restriction in upward gaze is experienced. Additionally, visual loss with aging may occur due to glaucoma, macular degeneration, and diabetic retinopathy. More commonly, visual losses may be due to cataracts which occur in $46 \%$ of individuals between the ages of 75-85 years $^{42}$.

\section{Implications for persons with developmental disabilities}

While specific information about the prevalence of visual problems in individuals with developmental disabilities is not available, it is likely that a greater number of people with developmental disabilities have uncorrected or unidentified visual problems than in the general population ${ }^{43}$. Good et al. ${ }^{44}$ reported that the incidence of cortical visual impairment (CVI) is increasing in children with neurological deficits. These authors speculated that better medical care has lowered the mortality rate of children with severe neurological problems and thus these children survive for longer periods of time. Although, the residual vision of the child with CVI often improves over time, the child may be left with diminished visual acuity. Additionally, adults with Down syndrome are at greater than normal risk for eye disorders such as cataracts, which also seem to occur at an earlier age than for matched age peers ${ }^{45}$. Cataracts are speculated to occur in about 50\% of adults with Down syndrome. Table 1 presents the percentage of individuals with Down syndrome who present with visual impairment compared to the general population and to individuals with mental challenges who are non-Down syndrome.

Table 1. Visual Impairments in the General Population and in Individuals with Mental Retardation ${ }^{35}$.

\begin{tabular}{cccc}
\hline $\begin{array}{c}\text { National Health } \\
\text { Interview Survey }\end{array}$ & $\begin{array}{c}\text { Level of Mental } \\
\text { Retardation }\end{array}$ & $\begin{array}{c}\text { Down } \\
\text { Syndrome }\end{array}$ & $\begin{array}{c}\text { Non-Down } \\
\text { Syndrome }\end{array}$ \\
\hline General Population & Mild/Moderate & & \\
$4.9 \%$ & $45-64$ years & $16.2 \%$ & $8.9 \%$ \\
$6.5 \%$ & $65-74$ years & $50 \%$ & $16.7 \%$ \\
& Severe/Profound & & \\
$4.9 \%$ & $45-64$ years & $39.2 \%$ & $17.7 \%$ \\
$6.5 \%$ & $65-74$ years & $75 \%$ & $17.6 \%$ \\
\hline
\end{tabular}

Another factor that may contribute to a high number of individuals with developmental disabilities having undiagnosed visual problems is the examiner's difficulty in gathering subjective information from the individual. The extent of visual loss may not be identifiable if the individual cannot respond to a standard eye chart consisting of letters, numbers, or words. In general, physiological changes in tandem with environmental and pre-existing disease factors 
in individuals with life-long disabilities may cause greater impairments in vision than would be anticipated in the general population ${ }^{46}$. Signs that might indicate a change in vision include rubbing the eyes, squinting, shutting or covering one eye, or tilting the head. Changes in daily functions such as stumbling during gait, hesitancy on steps or curbs, holding reading materials closer than usual, or sitting close to the television also might suggest visual changes.

Considerations that need to be made for individuals with developmental disabilities may include: early cataract removal before declining function impairs the individual's ability to cooperate with post- operative care; soft lighting; reduced glare in the environment; use of color; use of high contrast; or referral to a low-vision rehabilitation specialist. Reinforcement with tactile or verbal cues also may be necessary to improve visual responses.

\section{Hearing}

Prevalence studies indicate that 25 - $40 \%$ of individuals over the age of 65 years exhibit some degree of hearing loss with the most common cause of sensorineural hearing loss being presbycusis ${ }^{47}$. Presbycusis can be related to a number of factors including: cellular aging in the peripheral, auditory, and CNS pathways; acoustic trauma; cardiovascular disease; and cumulative effects of ototoxic medications ${ }^{48,49}$. Problems noted with presbycusis include a slowly progressive bilateral hearing loss, difficulty with word recognition, and a decline in perceptual processing of the temporal characteristics of speech.

\section{Implications for persons with developmental disabilities}

Conductive hearing losses can occur due to external ear disease and acute or chronic diseases of the middle ear. Otitis media (ie. inflammation of the middle ear) is one of the most common causes of conductive hearing loss. Individuals with developmental disabilities may be more likely to develop this type of hearing loss than the general population due to the occurrence of repeated otitis media that is undetected and untreated ${ }^{50}$. In particular, many people with Down syndrome have conductive hearing loss resulting from frequent middle ear infections in childhood ${ }^{51}$. Individuals with Down syndrome also have a propensity to sensorineural hearing loss which is associated with the general aging population. However, the sensorineural hearing loss in individuals with Down syndrome can begin to develop during the $2^{\text {nd }}$ decade of life.

Many adults with developmental disabilities can "hide" a hearing loss due to their limited communication abilities and sheltered life styles. Therefore, many aging adults with developmental disabilities may have an undetected hearing loss that interferes with an already limited communication ability and contributes to social isolation and depression. Seltzer and Luchterhand ${ }^{52}$ found that over half of the consumers who had been evaluated at the Aging and Developmental Disabilities
Clinic had significant hearing losses. Yet, for many of these individuals, the family and local service providers had not suspected a hearing loss. Clinical signs that might indicate a hearing loss include turning up the TV or radio very loud, speaking loudly, responding to questions inappropriately, or becoming confused in noisy environments.

Considering the possibility of a greater incidence of hearing losses in adults with developmental disabilities, health care providers should insist on audiologic testing for all individuals with developmental disabilities. However, the testing should be done by an audiologist with special training in evaluating persons with mental retardation or developmental disabilities. Hearing aids can be helpful in increasing responsiveness to sound, but only if tolerated by the wearer. For those who cannot tolerate hearing aids, functional hearing can be improved through minimizing background noise, facing the person being spoken to, and speaking slowly with good articulation. If the hearing loss is identified early, communication through use of sign language or augmentative communication might be used as an alternative strategy.

\section{Taste and Smell}

Evidence suggests that some older individuals experience less pleasure during meals due to impaired taste and smell which results from higher thresholds for these senses ${ }^{53}$. Increases in the thresholds of taste and smell may make food seem tasteless and less appealing. For individuals with developmental disabilities, this may cause changes in their oral motor skills, eating habits, and nutritional intake. A decreased appetite also may result as a side effect from some medications. With either of these two problems (decrease in taste and smell perceptions and side effects from medication), a lack of interest in food may occur and the nutritional health of the individual may be affected.

\section{Implications for persons with developmental disabilities}

Being under ideal body weight can be a problem for up to $25 \%$ of people with developmental disabilities ${ }^{54}$. In particular those individuals with lower levels of cognitive functioning and those with multiple disabilities and feeding difficulties are typically underweight. The lack of interest in eating because of changes in taste and smell in these individuals may lead to further debilitation, susceptibility to opportunistic infections, and even death. Nutritional supplements may be necessary for maintaining ideal body weight and meeting daily nutritional requirements. Additionally, emphasis should be placed on the visual appearance of food as well as on texture to increase the meal's appeal. Separating food rather than mixing food on a plate and varying textures of food might be actions to take to increase one's interest in eating. Use of condiments, other than salt, also may be used to increase overall flavor.

Dental problems also may cause problems with eating in individuals with developmental disabilities. The greatest dental problem faced by the adult with developmental disa- 
bilities is periodontal disease $\mathrm{e}^{55}$. The incidence of severe, destructive periodontal disease in individuals with DS may be as high as $96 \%{ }^{56}$. In this population, the disease is usually in evidence by the $3^{\text {rd }}$ decade of life. The immunologic deficiencies in persons with DS may be related to the increased prevalence and severity of periodontal disease ${ }^{57,58}$.

\section{Somatosensory}

Although the degree of change may vary in individuals, touch and the related senses of proprioception and kinesthesia appear to decrease with age. Age related changes that contribute to problems with touch and position sense have been noted in the peripheral nervous system both anatomically as well as physiologically ${ }^{59-62}$. Additionally, action potentials may take longer than usual to reach the central nervous system in the aging adult. This delay is due to a gradual shortening of the internodal length that contributes to an increased conduction velocity.

Quantitative studies have shown that a progressive impairment of sensory detection occurs with aging. An example of this gradual decline is the perception of touch /pressure which approaches a fourfold reduction in men over age 40 years ${ }^{63}$. Schmidt et al. ${ }^{61}$ found an age related decline in response to "flutter" and "tap", which they related to changes in the peripheral sensory units rather than conduction along the afferent nerves.

Proprioception has been reported as being similar in young and older subjects without disabilities ${ }^{64}$. However, passive movement thresholds have been reported to be twice as high for the hip, knee, and ankle in subjects over 50 years of age compared with subjects less than 40 years of age ${ }^{65}$. No change in upper extremity perception was noted. Skinner et al. ${ }^{66}$, in a study of knee joint position sense, found that the abilities to reproduce passive knee position and to detect motion deteriorated with age.

\section{Implications for persons with developmental disabilities}

Loss of somatosensory function in aging adults with developmental disabilities may be devastating. For the individual who depends on tactile input to guide movement, the decrease in tactile function may lead to decreases in movement and possibly result in immobility. For example, the individual may no longer be able to access communication boards or to independently propel a wheelchair without sustaining injuries to the upper extremities. (Figure 2).

With the loss of proprioceptive abilities, particularly in the lower extremities, functional patterns of movement may be loss. For example, many adults with neuromotor disorders propel their wheelchairs with their feet. (Figure 3). If joint sense is decreased or lost in the hips, knees , and ankles, the coordination needed for efficiently moving from one place to another in the wheelchair may be compromised. If the individual is ambulatory, a loss of proprioceptive abilities with age may necessitate use of a different is ambulatory, a loss

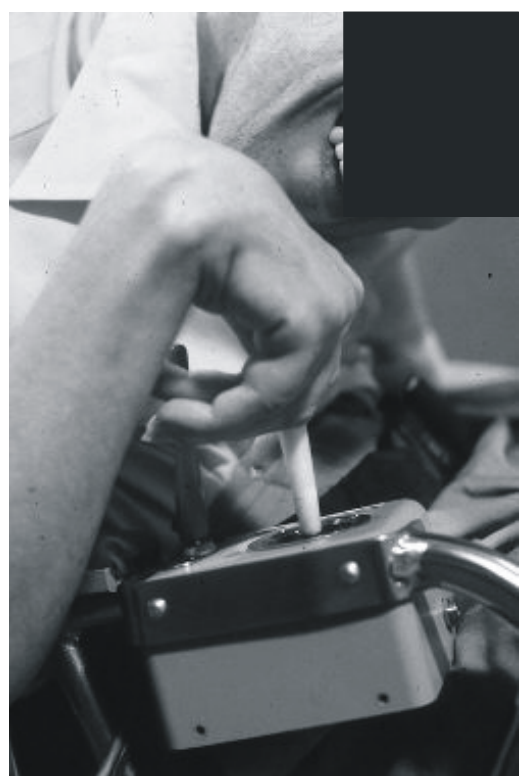

Figure 2. Use of abnormal posturing to access hand held controls.

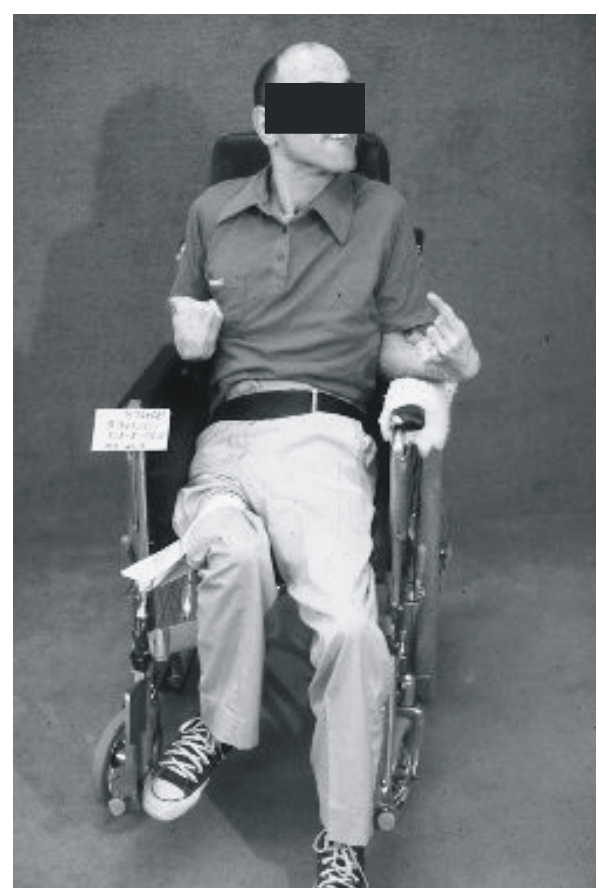

Figure 3. Individual propelling wheelchair using feet.

of proprioceptive abilities with age may necessitate use of a different type of ambulation assist, such as a walker rather than crutches or canes. Assistance from another person during ambulation may be necessary for some individuals who are not longer "safe" during independent ambulation due to loss of proprioceptive function. 


\section{EFFECTS OF AGING ON THE NEURO- MUSCULOSKELETAL SYSTEM}

\section{Flexibility}

Changes in collagen are a biological cause for decreases in flexibility as one ages. With age, collagen fibers become irregular in shape owing to cross-linking. This pattern results in a decreased linear pull relationship in the collagen tissue and leads to a decreased mobility in the body's tissues ${ }^{67}$. Poor nutrition also may lead to collagen changes and this problem maybe seen in the population with developmental disabilities. In particular, deficiency of Vitamin C appears to interfere with normal tissue integrity and may affect muscle functioning and elasticity of collagen.

Muscles, skin, and tendons become less flexible and mobile as one ages. The spine also becomes less flexible due to collagen changes in the annulus and to decreased water content in the nucleus pulposa. Furthermore, osteoporotic changes in the vertebral bones may lead to fractures of the vertebrae, increased collagen scarring, and decreased flexibility of the spine.

Hypokinesis or decreased activity can be a functional cause of loss of flexibility. Older individuals who remain sitting or immobile for long periods of time may develop tightness in those muscles that are shortened in that particular position and which may form collagenous adhesions. In particular, decreased passive and active range of motion particularly in the flexor musculature may be seen in elders who sit for extended periods of time during the day.

\section{Implications for persons with developmental disabilities}

Loss of flexibility in the aging adult with developmental disabilities may be even more dramatic than for the typical aging adult. In individuals with neuromotor disorders, loss of flexibility may be considered a secondary condition. A secondary condition is defined as an injury, impairment, functional limitation, or disability that occurs as a result of the primary pathology ${ }^{68}$. These secondary conditions in older persons with cerebral palsy (CP) may be seen due to multiple body systems which were affected during the developmental years. If the individual has been inactive, adequate bone density and mass may not have been developed at a younger age. Therefore, that individual is likely to experience an accelerated loss of bone density and mass with age. Recently a link between lifelong use of Dilantin and osteoporosis has been documented ${ }^{69}$. This risk appears to be particularly high in individuals who are non-ambulatory or sedentary. Many physicians recommend that regular periods of sunlight be part of a daily schedule to offset the effects of Dilantin on bone loss in those individuals who are at greatest risk. Additionally, persons with neuromotor problems may be at an increased risk for osteoporosis due to limitations in mobility, inadequate calcium intake in the diet, and decreased sun exposure leading to low circulating levels of vitamin $\mathrm{D}^{70}$. In
1998, Center, Beange and McElduff ${ }^{71}$ in a study of men and women with mental retardation with a mean age of 35 years found a bone mineral density more than 2 standard deviations below that of an age and gender matched population. Osteoporotic risk factors include low body weight, small body size, hypogonadism, endocrine disorders, sedentary lifestyle, and poor nutrition. All of these factors commonly are found in individuals with developmental disabilities.

A pathological cause of loss of flexibility in persons of any age is arthritis. Osteoarthritis (OA), a commonly occurring disorder in the elderly, is characterized by deterioration of articular cartilage and formation of new bone in the subchrondeal areas as well as at the margins of the joint ${ }^{72}$. Arthritic changes in the joints of aging adults with developmental disabilities may be noted at even earlier ages. Osteoarthritis has been cited as a cause of pain as well as loss of flexibility in individuals with $\mathrm{CP}^{10,73}$. The increasing biomechanical stress on multiple joints in individuals with severe neuromuscular dysfunctions or bony abnormalities may increase the incidence and likelihood of OA. Murphy et al. ${ }^{10}$ speculated that the development of pain in weight bearing joints in adults with CP was a sign of early degenerative arthritis. Cathels and Reddihough $^{73}$ found clinical evidence of arthritis in $27 \%$ of a group of 149 adolescents and young adults with CP. Individuals who walked were more affected than those who did not walk. Trauma to a joint predisposes it to OA, as has been noted in the high incidence of OA in the shoulders and elbows of baseball pitchers, ankles of ballet dancers, and knees of basketball players. Therefore, disturbances of the joint mechanics or repeated abnormal stresses to a joint in those individuals who are ambulatory may predispose them to early onset OA. Pain and weakness usually are associated with OA, but in individuals with developmental disabilities who cannot communicate easily, these symptoms may be missed or misinterpreted ${ }^{74}$.

Arthritic changes in different joints also may lead to loss of functional abilities in individuals with developmental disabilities. For example, the ability to transfer oneself from a wheelchair to the bed or tub may become extremely difficulty if soreness in the shoulders, elbows, and wrists is experienced. Many individuals who were ambulatory may opt to use a wheelchair if pain is experienced in the spine, hips, knees, or ankles during walking activities. Additionally, more adaptive equipment may be necessary in the home in order for the person to be as independent as possible with activities of daily living.

\section{Strength}

Muscle strength, as defined by the ability to produce force or torque, declines with age in both men and women ${ }^{75-}$ ${ }^{78}$. A common change noted in aging muscle is reduction of mass, from $25 \%$ to $43 \%$, depending upon the activity level of the individual ${ }^{79}$. Additionally, decreased strength may be due to smaller numbers of muscle fibers and muscle motor 
units, as well as a decrease in size of the muscle fibers. Functioning motoneurons also appear to decline with aging and thus problems may be noted in coordination and speed of muscle contraction.

Decreases in muscle strength as a person ages may be related to decreased time spent in vigorous work or athletic activities. Some studies have shown a loss of 18 - 20 percent of maximum force by age 65 years while others demonstrate a loss of up to 40 percent $^{80}$. Muscles that appear most likely to show a decrease in muscle strength during periods of inactivity are the active antigravity muscles, such as the quadriceps, hip extensors, ankle dorsiflexors, latissimus dorsi, and triceps.

\section{Implications for persons with developmental disabilities}

Individuals with physical disabilities have been noted to experience additional problems in the musculoskeletal system as they age $\mathrm{g}^{62,64,81}$. The musculoskeletal problems may be related to deformities such as subluxations and dislocations of the hip, abnormalities of the foot, patella alta, scoliosis, pelvic obliquity, and contractures. These musculoskeletal problems may cause secondary conditions, such as decreased strength, due to the inability of the individual to move in a variety of patterns.

Strauss et al. ${ }^{28}$ in their study of 8733 persons with cerebral palsy found that among young adults (age 20), 39\% were able to walk well without support at least 20 feet, while $35 \%$ did not walk even with support. However, at age 60, only $25 \%$ were able to walk well along and $40 \%$ did not walk at all. These researchers speculated that therapeutic approaches should be designed to promote muscle strengthening in order to avoid surgical procedure that produce muscle weakening. They also speculated that loss of muscle strength in individuals who have had difficulty with movement all of their lives may be even greater than that expected solely due to the aging process. Janicki and Jacobson ${ }^{82}$, in a study of over 10,000 individuals who were mentally challenged, found that a decline in motoric skills began at about 50 years of age, even for those who were mild to moderately challenged. Among those who were more severely and profoundly challenged, motoric skills remained relatively stable until they reached the late 70's. However, this delayed decline was related most probably to more limited motoric abilities even at younger ages when compared with the individuals with mild to moderate mental retardation. How the aging process affects the "strength" of persons with neuromotor problems has not been well studied. However, it appears that at least some persons with neuromotor problems experience increasing problems with movement as they age.

Strength training is a popular form of exercise for individuals both with and without disabilities. However, questions have been raised over time about the appropriateness of such programs with individuals with spasticity. Andersson et al. ${ }^{83}$ found that a progressive strength training program provided significant improvement in isometric strength (hip extensors $\mathrm{P}=0.006$, hip abductors $\mathrm{P}=0.01$ ) and in isokinetic concentric work at $30 \%$ s (knee extensors $\mathrm{P}=0.02$ ) in individuals (ages 25 - 47 years) with spastic diplegia. The results of the intervention also revealed significant improvements in the Gross Motor Function Measure dimensions D (standing) and E (walking, running and jumping) as well as in the Timed Up and Go test. No increase in spasticity as measured by the modified Ashworth Scale was noted in individuals who underwent strength training.

Therefore, as with most adults, moderate regular exercise is essential for maintaining mobility in adults with developmental disabilities. Loss of even a small amount of strength may lead to loss of functional abilities in this population because of the very sensitive balance between muscle groups that has been developed over time for some functional activities. Weakness can result in loss of functional abilities, such as climbing stairs ${ }^{28}$, transferring, or getting out from a chair. Additional, increased occurrences of complications such as pressure sores, contractures ${ }^{10}$, and pneumonia may result from immobility in some adults who have lifelong limitations in movement. Bed rest or chair rest should be avoided if at all possible and gross motor activities should be included as a part of the day's activities.

\section{Posture and Positioning}

Upright posture, either in sitting or in standing, seems to demonstrate the most noticeable changes as one ages. Sitting postures change in many older adults with the head held forward, the shoulders rounded, and the upper back kyphotic. In sitting or standing, a flatter lumbar lordosis may be seen in the low back. In standing, flexion at the hips and knees may be more noticeable. These changes in the spine and in the lower extremities most frequently are caused by changes in the intervertebral $\operatorname{disk}^{84-88}$ as well as to decreased mobility or hypokinesis ${ }^{89}$.

\section{Implications for persons with developmental disabilities}

The spine may be a focal point of difficulty with persons with lifelong disabilities. A scoliosis that has been present since childhood may further progress as the individual ages.

In particular, older persons with $\mathrm{CP}$ who have been immobile or relatively inactive may not have developed adequate bone density and mass at a younger age and are likely to experience an accelerated loss of bone density and mass as they age. Individuals with severe scoliosis (eg. $\left.>45^{\circ}\right)^{90}$ may have increasing problems with mobility and hygiene care resulting in greater dependency on care givers ${ }^{91,92}$. Murphy et al. ${ }^{10}$ found scoliosis present in over half of their study population with severe scoliosis especially common in the nonambulatory group.( Figure 4).

In individuals who have taken medications for seizure disorders, a decrement in bone mineral density may be noted. Hauser and Hesdorffer ${ }^{93}$ found a high coexistence of seizures 
and cerebral palsy and stated that individuals with both these disorders are at a greater risk for osteoporosis than would be anticipated. This increased risk for osteoporosis may cause a predisposition for fracture rates at earlier ages than in the general population. For example, compression fractures of the spine may be noted with increased frequently in those individuals with seizure and neuromotor disorders and the resultant pain from the fractures may further contribute to hypokinesis.

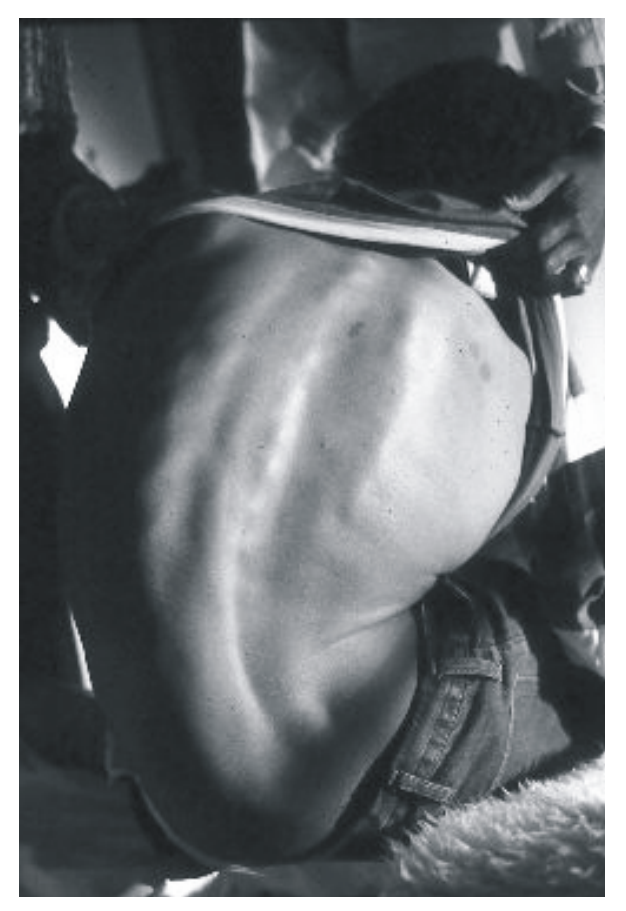

Figure 4. Severe scoliosis in adult with developmental disability.

Clinical suggestions for older individuals with developmental disabilities are similar to those given to other aging individuals. Increased activity in positions other than supine or sitting are suggested along with increased weight bearing positions. Caution, however, must be taken regarding the amount of stress that is placed on joints that have been misaligned for many decades. In many cases, therapists and others dealing with aging individuals with developmental disabilities must realize that they are dealing with structures that have never been "normal”. Therefore, some procedures used with geriatric clients without developmental disabilities or with children with developmental disabilities may not be appropriate. For example, placing an individual with a severe scoliosis in a sidelying position should be attempted only with close supervision since fractures of the rib cage may occur due to long term osteoporosis. Stretching of contractures that have been long term also should be performed with much caution due to the risk of fracture if undue pressure is placed around the joint.

\section{Fractures}

Fractures have been documented as occurring at any time during the lifespan of an individual with $\mathrm{CP}^{70,94-96}$. Fractures may occur due to a variety of reasons with the combination of osteoporosis, long lever arms, and contractures being cited as increasing the risk of nontraumatic fractures. Brunner and Doderlein ${ }^{96}$ identified a total of 54 non-traumatic fractures in 37 individuals with CP over a 20 year period of time. The fractures were found to have occurred between the ages of $12-16$ years with the most common site being the supracondylar region of the distal femur. These researchers identified hip dislocations or contractures of major joints as being predisposing factors to the fractures. Futhermore, they found that $41 \%$ of the fractures occurred within 9 months of surgery and that the majority of the fractures occurred during physical therapy intervention. The fractures not associated with surgery occurred during activities of daily living. Brunner and Doderlein ${ }^{96}$ also described stress fractures occurring at the patella associated with a crouched gait and over-activation of the quadriceps. These findings further illustrate the importance of maintaining good "bone" health in individuals with CP through exercise, strengthening, and prevention of injuries.

\section{Gait and Balance}

Changes in stance and gait with aging may be affected by changes in (1) the ability of the body to carry out the appropriate response via the effector system (strength, range of motion, flexibility, and endurance), (2) processing of input from the visual, vestibular, and somatosensory (primarily proprioceptive) systems and, (3) central processing or the ability of the body to determine, in advance, the correct appropriate sequence of responses . Changes noted with aging via the effector system include: mild rigidity; slowed postural reaction times; decreased stride length; increased stride width; decreased accuracy and speed; decreased vertical displacement; decreased excursion of legs during swing phase; decreased rotation of the trunk; and decreased velocity of limb motions ${ }^{97}$. Additionally, decreased back extension and neck range of motion may interfere with upright posture and balance. Schenkman ${ }^{98}$ reported that loss of flexibility may lead to impaired response strategies during stance and ambulation which could result in falls.

Inadequate processing of proprioceptive input may interfere with the adequate processing of information regarding motion of the body with respect to the support surface and to motion of the body segments and lead to poor balance. Additionally, older adults may have increased response times due to poor central processing of sensory information ${ }^{99-101}$. This delay in response has been speculated as contributing to instability during stance and ambulation in older persons who fall. For example, a loss of balance was noted in older subjects during a study in which they were asked to quickly 
perform unilateral knee flexion during standing ${ }^{99}$. Data from this study suggested that changes in coordination of movement and in posture were age related. Different strategies for responding to unexpected postural perturbations also have been noted in older adults in comparison with healthy young adults. A higher incidence of proximal to distal sequencing has been noted in older adults than in young adults ${ }^{100}$. This change in the sequencing pattern has been speculated as being an indicator of altered postural control and central processing in the older adult.

\section{Implications for persons with developmental disabilities}

As persons with developmental disabilities become older, they become more like those in their non-disabled peer group in relationship to gait and balance problems. Problems may be noted in walking due to presence of arthritis and bunions (which have a 90\% incidence in persons with Down syndrome $)^{102}$. Years of toe walking and cavus foot deformities in some individuals can lead to pain in the metatarsal heads and difficulty during walking. (Figure 5). However, in persons with $\mathrm{CP}$, ambulation and balance appear to decline at an earlier age than in the general population due to earlier declines in the vestibular system ${ }^{103}$. The risk of falling, therefore, may occur at an earlier age as well. Center et al. ${ }^{71}$ found that falls were the $2^{\text {nd }}$ most likely cause of injury in a group of persons with MR who were institutionalized. These researchers found that individuals with MR were 3.5 times more likely to have a fracture than the general population. Additionally, the fracture rate was higher among those who could ambulate independently and among those who needed assistive devices to ambulate. Persons with CP also are at an increased risk for falls and fractures than their contemporaries and therefore may become less mobile at an earlier age ${ }^{104}$. A further complication for persons with neuromotor problems is the deconditioning that occurs after a hip fracture or dislocation that necessitates a reduction in the daily amount of gross motor activity. Some individuals who were ambulatory prior to a hip fracture may never again attain the coordination or endurance needed for independent ambulation. Compression fractures of the spine also may contribute to pain and loss of upright mobility. For older individuals who have lost functional ambulation, consideration should be given for use of a wheelchair or other adaptive equipment.

Although independent ambulation may not be possible for the older individual with developmental disabilities, daily amounts of moderate regular exercise are essential to maintain mobility. Appropriate exercise can improve strength, flexibility and balance, and therefore reduce the chance of future falls and injuries. Additionally, research has shown that the presence of mobility and ambulation appears to influence the risk of mortality in persons with mental retardation regardless of living arrangements $\mathrm{s}^{4,28,105,106}$.

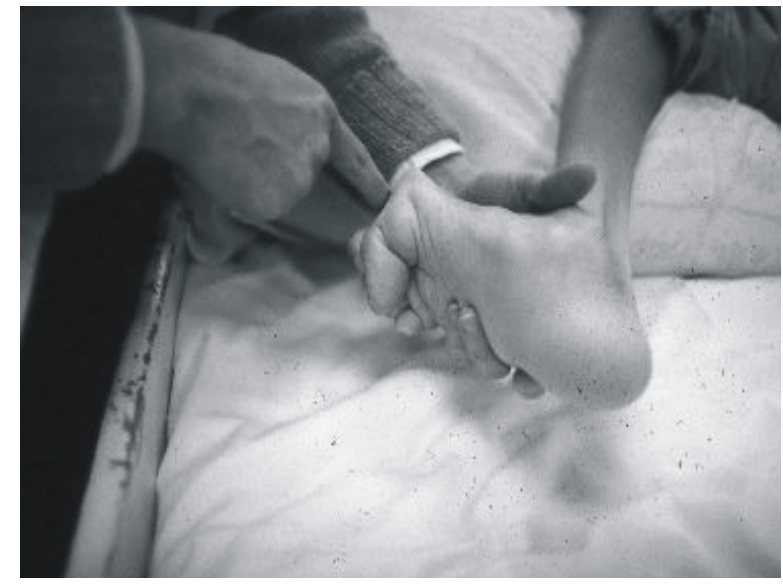

Figure 5. Long standing deformity of foot.

\section{Cardiopulmonary changes during the Aging Process}

\section{Anatomic and Physiologic changes}

Most researchers agree that changes in cardiac and pulmonary function occur as one ages, regardless of life style. Beginning at about 24 years of age, persons begin having a progressive decrease in chest wall and bronchiolar compliance due to structural changes in the bones, cartilage and elastic structures ${ }^{107}$. As has been discussed previously, cross-linking of collagen fibers occurs and a decrease in resiliency of elastic and cartilaginous tissue occurs. The elastic fibers in the lungs also are compromised resulting in increased lung compliance and decreased elastic recoil ${ }^{108,109}$.

A decreased efficiency of gas exchange occurs as one ages due to loss of tissue from the alveolar walls and septra as well as an increase in the size and number of alveolar fenestra ${ }^{110,111}$. These changes contribute to a decreased surface area available for gas exchange. Additionally, an increase in the work of breathing occurs due to increased rigidity of the conducting tubules, changes in smooth muscle structure, and increased thickness of the mucosal bed ${ }^{112,113}$.

The total lung compliance changes that are noted with age have an important impact on the pulmonary function of an individual. Vital capacity declines while functional residual capacity and residual volume increase with advancing age ${ }^{114}$. The vital capacity for a 65 year old has been found to be about $77 \%$ of that of a 25 year old. In contrast, the percentage of the total lung capacity that is residual volume in the 65 year old rises to $38.5 \%$ from $29.5 \%$ for women and $34.5 \%$ from $25.3 \%$ for men when comparisons are made with 25 year old individuals. Forced expiratory volume also decreases as one ages due to a loss of elastic recoil. The percentage of vital capacity that an individual can force out of the lungs in one second is about $84 \%$ in the 25 year- old individual, 
but only approximately 74 - 77\% in the elderly. However, the closing volume, which is the lung volume at which small airways begin to close, increases with age. The decrease in forced expiratory volume and the increase in closing volume contribute to the presence of physiologic and anatomic dead space in the lungs, thus, leading to decreased oxygenation of the blood.

Pulmonary gas exchange functions also are affected by age. Reduced distribution of blood flow in the lung is realized due to increased resistance to gas exchange in the small pulmonary blood vessels. These changes contribute to an increase in the mean pulmonary arterial pressure, reduction of the diffusion capacity, and less circulation in the aerated portions of the lungs.

\section{Implications for persons with developmental disabilities}

Kapell et al. ${ }^{35}$ found that people with MR have a greater incidence of non-ischemic heart disease when compared with their age and gender matched peers in the general population.

Additionally Anderson ${ }^{37}$ found that the most common chronic health problems in older adults with MR who lived in community settings included high blood pressure and heart disease. However, the prevalence of other types of heart and pulmonary disease is unknown among persons with developmental disabilities. For some individuals with developmental disabilities, the risk for some of the age - associated problems such as high cholesterol may actually be less than for the general population due to restrictions in lifestyle such as the inability to smoke, drink alcohol, or overeat.(Table 2).

Exercise programs are as important in improving cardiovascular fitness in persons with developmental disabilities as in the general population. Evidence exists that minimally supervised exercise programs for adults with developmental disabilities can result in improved cardiovascular fitness ${ }^{116-118}$. For persons with severe physical disabilities, the physical, occupational, or recreational therapist should be consulted during the development of the exercise program.
For more minimally involved individuals, adapted physical education curriculums may be appropriate.

Persons with developmental disabilities have other problems, however, with respiratory diseases. Respiratory disease, historically, has been a major cause of death in individuals with developmental disabilities. The increased mortality in the developmentally disabled population due to respiratory infections is attributed to the presence of cerebral palsy, epilepsy, and reduced efficiency in coughing, feeding, and breathing ${ }^{25}$. Ferrang, Johnson, and Ferrara ${ }^{119}$ found that over half of adults with cerebral palsy in their study had more problems with feeding as they aged. Many of the adults interviewed reported that they were experiencing less control of their tongue than in the past and that often food slid uncontrollably down the throat resulting in coughing and gagging. These changes certainly could lead to aspiration and pneumonia in some persons. These oral motor problems appear particularly common in individuals with spastic type cerebral palsy ${ }^{120}$. For individuals with Down syndrome, respiratory disease, infection, congenital heart disease, or a combination of the three are the major causes of death ${ }^{121}$.

\section{Cognitive Changes in Individuals with Down syndrome}

Cognitive changes in about $1 / 3$ of individuals with Down syndrome after age 35 years have been noted ${ }^{15}$. These cognitive changes have been associated with neuropathological changes in the brain of individuals with Down syndrome and with signs similar to patterns seen with Alzheimer's Disease. Wisniewski et al. ${ }^{15}$ identified loss of vocabulary, recent memory loss, impaired short-term visual retention, difficulty in object identification, and loss of interest in surroundings as early cognitive changes. Dalton and Crapper ${ }^{122}$ described memory loss in persons with Down syndrome ages 39 - 58 years over a 3 year period of time. Four of the 11 subjects deteriorated over the 3 years to the point that they could no longer learn a simple discrimination task. Fenner et al. ${ }^{123}$ found that the greatest decline in function was in a 45 - 49 year-

Table 2. Hypertension and Ischemic Heart Disease in the General Population and in Individuals with Developmental Disabilities ${ }^{36}$.

\begin{tabular}{cccc}
\hline Pathology & $\begin{array}{c}\text { National Health } \\
\text { Interview Survey }{ }^{115} \\
\text { ( General Population) }\end{array}$ & $\begin{array}{c}\text { Down } \\
\text { Syndrome }\end{array}$ & $\begin{array}{c}\text { Individuals } \\
\text { with DD } \\
\text { (Non- Down } \\
\text { Syndrome) }\end{array}$ \\
\hline Hypertension & & & \\
45 - 64 years & $21.7 \%$ & $1.7 \%$ & $23.6 \%$ \\
$65-74$ years & $34.3 \%$ & $9.1 \%$ & $21.7 \%$ \\
Ischemic Heart Disease & & & \\
$45-64$ years & $4.6 \%$ & $3.4 \%$ & $4.1 \%$ \\
$65-74$ years & $13.2 \%$ & $9.1 \%$ & $13.0 \%$ \\
\hline
\end{tabular}


old group. Fortunately, Hewitt and Jancar ${ }^{124}$ found that less than $50 \%$ of persons with Down syndrome will develop dementia symptoms associated with Alzheimer's disease.

Physical therapists and occupational therapists should be aware of early signs of dementia in persons with Down syndrome and be prepared to intervene as necessary to retain as much adaptive functioning as possible. Higher functioning persons with Down syndrome will present with the same signs of Alzheimer's disease as noted in the general population $^{18}$. These signs include memory loss, temporal disorientation, and decreased verbal output. Early signs of dementia in lower functioning persons with Down syndrome might include apathy, inattention, decreased social interaction, daytime sleepiness, gait deterioration, and seizures.

\section{CONCLUSIONS}

Physical therapists and occupational therapists should be effective health advocates and health care providers for the person with developmental disabilities throughout the life span. However, the aging of this special population presents major challenges to most therapists. Although persons with developmental disabilities share similar changes and risks of aging as other persons their age, the presence of life long physical and cognitive disabilities presents special challenges. At some point in time, individuals with developmental disabilities may need rehabilitation rather than habilitation in order to regain abilities after injury or illness. An understanding of the effects of aging on the general population plus identification of special implications for persons with developmental disabilities is mandatory for health care professionals, including physical therapists and occupational therapists, who wish to provide appropriate intervention.

\section{REFERENCES}

1. Eyman R, Call T, White J. Life expectancy of persons with Down syndrome. Am J Ment Retard 1991; 95: 603-612.

2. Strauss D, Eyman R. Mortality of people with mental retardation in California with and without Down Syndrome, 1986 1991. Am J Ment Retard 1996; 100: 643-653.

3. US Bureau of the Census. Washington, DC: United States Government Printing Office; 1997.

4. Borros M, Feliciangeli A, Sciuto L, et al. Functional status of adults with cerebral palsy and implications for treatment of children. Dev Med Child Neurol 2001: 43: 516 - 528.

5. Bax M, Smyth D, Thomas A. Health Care and physically handicapped young adults. British Medical Journal. 1988; 296; 1153 $-1155$.

6. Singhal B, Mathew KM. Factors affecting mortality and morbidity in adult spina bifida. Eur J Pediatr Surg 1999; 9 ( Suppl 1); $31-32$.
7. Hemming K, Hutton JL, Pharoah POD. Long-term survival for a cohort of adults with cerebral palsy. Dev Med Child Neurol 2006; 48: 90 - 95.

8. Eyman RK, Grossman HJ, Chaney RH, et al. Survival of profoundly disabled people with severe mental retardation. AJDC 1993; 147: 329-336.

9. Martin BA. Primary care of adults with mental retardation living in the community. Am Fam Physician.1997; 56: 485-494.

10. Murphy KP, Molnar GE, Lankasky K. Medical and functional status of adults with cerebral palsy. Dev Med Child Neurol 1995; 37: 1075-1084.

11. Developmental Disabilities Act, Public Law 98-527, U.S. Congress, Senate, 98th Congress, 1984.

12. American Association on Mental Retardation. Mental retardation: Definition, classification, and systems of supports. Washington, D.C.: American Association on Mental Retardation;1992.

13. Janicki MP, Hogg JH. International research perspectives on aging and mental retardation: An introduction. Australia and New Zealand Journal of Developmental Disabilities 1989;15: 161164.

14. Ball MJ, Nuttall K. Neurofibrillary tangles, granuovascular degeneration, and neuron loss in Down syndrome: Quantitative comparison with Alzheimer dementia. Annals of Neurology 1980; 7: 462- 465.

15. Wisniewski KE, Wisniewski HM, Wen GY. Occurrence of neuropathological changes and dementia of Alzheimer's disease in Down syndrome. Annals of Neurology 1985; 17: 278-282.

16. Burt DB, Loveland KA, Lewis KR. Depression and the onset of dementia in adults with mental retardation. Am J Ment Retard 1992; 96: 502-511.

17. Zigman W, Schupf N, Haveman M, et al. Epidemiology of Alzheimer Disease in Mental Retardation: Results and Recommendations from an International Conference. Washington, DC: American Association on Mental Retardation; 1995.

18. Evenhuis HM. The natural history of dementia in Down's syndrome. Archives of Neurology. 1990:47:263-267.

19. Barcikowska M, Silverman W, Zigman W, et al.. Alzheimer-type neuropathgology and clinical symptoms of dementia in mentally retarded people without Down syndrome. Am J Ment Retard. 1989; 93: 551-557.

20. Popovitch ER, Wisniewski HM, Barcikowska M, et al. Alzheimer neuropathology in non-Down's mentally retarded adults. Acta Neuropathol 1990; 80: 362-367.

21. Janicki MP, MacEachron AE. Residential, health and social service needs of elderly developmentally disabled persons. Gerontologist $1984 ; 24: 128-137$.

22. Janicki MP, Otis JP, Puccio PS, et al.. Service needs among older developmentally disabled persons. In: Janicki MP, Wisniewski HM, eds. Aging and Developmental Disabilities, Issues and Approaches. Baltimore, MD: Paul H. Brookes; 198514. US Bureau of the Census. Statistical Abstract of the United States, ed 111. Washington, DC: United States Government Printing Office; 1991.

23. Ansello EF. The intersecting of aging and disabilities. Educational Gerontology 1988:14:351-363. 
24. Eyman R, Grossman H, Tarjan G, Miller C. Life expectancy and mental retardation: A longitudinal study in a state residential facility. Washington, DC: American Association on Mental Deficiency: 1987.

25. Carter G, Jancar J. Mortality in the mentally handicapped: A fifty year survey at the Stoke Park group of hospitals (1930 1980). J of Ment Defic Res. 1983: 27:143-156.

26. Strauss D, Shavelle R. Life expectancy of adults with cerebral palsy. Dev Med Child Neurol. 1998; 40: 369 - 375.

27. Strauss D, Shavelle R. Life expectancy of persons with chronic disabilities. J Insur Med. 1998; 30: 96 - 108.

28. Strauss D, Ojdana K, Shavelle R, Rosenbloom L. Decline in function and life expectancy of older persons with cerebral palsy. NeuroRehabilitation 2004; 19: 69 - 78

29. Blair E, Watson L, Badawi N, Stanley FJ. Life expectancy among people with cerebral palsy in Western Australia. Dev Med Child Neurol. 2001; 42: 508 - 515.

30. Hutton JL, Cooke T, Pharoah POD. Life expectancy in children with cerebral palsy. British Medical Journal. 1994; 309: 431 435.

31. Eyman RK, Call TL, White JF. Life expectancy of persons with Down syndrome. Am J Mental Retard. 1991; 95: 603-612.

32. Jacobson JW, Sutton MS, Janicki MP. Demography and characteristics of aging and aged mentally retarded persons. In Janicki MP, Wisniewski HM (eds). Aging and developmental disabilities, issues and approaches. Baltimore, MD: Paul H. Brookes; 1985.

33. O’Brien KF, Tate K, Zaharia ES. Mortality in a large southeastern facility for persons with mental retardation. AJMD 1991:95: 497-503.

34. Shavelle R, Strauss D. Mortality of persons with developmental disabilities after transfer into community care. Am J Mental Retard. 1999: 104; 143- 147.

35. Kapell D, Nightingale B, Rodriquez A, et al. Prevalence of chronic medical conditions in adults with mental retardation: comparison with the general population. Ment Retard.1998; 36: $269-279$.

36. Beuhler B, Smith B, Fifield M. Medical issues in serving adults with developmental disabilities. In Technical Report \# 4. Logan, UT: Utah State University Developmental Center for Handicapped Persons. 1985.

37. Anderson DJ. Health Issues. In Sutton E, Factor AR, Hawkins BA, Heller T , Seltzer GB. Older Adults with Developmental Disabilities: Optimizing Choice and Change. Baltimore, MD: Paul H. Brookes; 1993.

38. Fozard JL, Wolf E, Bell B, et al. . Visual perception and communication. In Birren JE, Schaie KW (eds). Handbook of the Psychology of Aging, New York, NY: Van Nostrand Reinhold; 1977.

39. Cohen MM, Lessell S. The neuro-ophthalmology of aging. In Albert ML (ed). Clinical Neurology of Aging. New York, NY: Oxford University Press; 1984

40. Kallman H, Vernon MS. The aging eye. Postgraduate Medicine. 1987: 81: 2
41. Lowenfield IR. Pupillary changes related to age. In Thompson HS (ed). Topics in Neuro-Ophthalmology. Baltimore, MD: Williams \& Wilkins; 1979.

42. Kini MM, Liebowitz HM, Colton T, et al. Prevalence of senile cataract, diabetic retinopathy, senile macular degeneration, and open-angle glaucoma in the Framingham eye study. American Journal of Ophthalmology 1978: 85; 28-34.

43. Aitchison C, Easty DL, Jancar J. Eye abnormalities in the mentally handicapped. J of Ment Defic Res 1990: 34; 41 - 48.

44. Good WV, Jan JE, deSa L, et al.. Cortical visual impairment in children: a major review. Survey of Ophthalmology 1994: 38;351-364.

45. France TD. Ocular disorders in Down syndrome. In Lott IT and McCoy EE ( eds). Down syndrome: Advances in medical care. New York, NY: Wiley-Liss, Inc.; 1992

46. Heath JM. Vision. In Ham RJ, Sloane PD(eds) Primary care geriatrics. St. Louis, MO: Mosby Year Book; 1992.

47. Bess FH, Lichtenstein MJ, Logan SA. In Rintelmann WF (ed) Hearing assessment. 2nd Ed. Austin, TX: PRO-ED; 1991.

48. Keim RJ. How aging affects the ear. Geriatrics 1977: 32: 97 99.

49. Lowell SH, Paparella MM. Presbycusis: That is it ? Laryngoscope 1977:87; $1710-1717$.

50. Northern JL, Downs MP. Hearing Loss in Children ( 4th ed). Baltimore, MD: Williams \& Wilkins; 1991.

51. Young, C. V. Developmental disabilities. In Katz, J. (Ed.). Handbook of Clinical Audiology. (4th Ed.). Baltimore, MD : Williams \& Wilkins ;1994.

52. Seltzer GB, Luchterhand C. Health and well-being of older persons with developmental disabilities: A clinical review. In Seltzer MM, Krauss MW, Janicki MP (eds) Life Course Perspectives on Adulthood and Old Age. Washington, DC: American Association on Mental Retardation; 1994.

53. Stevens JC, Cain WS. Smelling via the mouth: Effect of age. Perception \& Psychophysics. 1986: 40: 142.

54. Similia S, Niskanen P. Underweight and overweight cases among the mentally retarded. AJMD. 1991:35; $160-164$.

55. Glassman P. New models for improving oral health for people with special needs. Journal of California Dental Association. 2005; 33: 625-633.

56. Barnett ML, Press KP, Friedman D, et al.. The prevalence of periodontitis and dental caries in a Down's syndrome population. J Peridontol. 1986: 57; 288-293.

57. Giannoni M, Mazza AM, Botta R, et al.. Dental problems in Down’s syndrome. Dental Cadmos. 1989: 57; 70 - 80.

58. Modeer T, Barr M, Dahllof G. Periodontal disease in children with Down’s syndrome. Scand J Dental Res. 1990: 98; 228 234.

59. Sabin TD, Venna N. Peripheral nerve disorders in the elderly. In Albert ML (ed). Clinical Neurology of Aging. New York, NY: Oxford University Press; 1984.

60. LaFratta CW, Canestrari RE. A comparison of sensory and motor nerve conduction velocities as related to age. Arch Phys Med Rehabil. 1966:47;286-290. 
61. Schmidt RF, Wahren LK, Hagbarth KE: Multiunit neural responses to strong finger pulp vibration. I. Relationship to age. Acta Physiol Scand. 1990: 140;1-10.

62. Mufson EF, Stein DG. Degeneration in the spinal cord of old rats. Exp Neurol 1980: 70; 179-186.

63. Dyck PJ. Schultz PW, O’Brien PC. Quantitation of touch-pressue sensation. Arch Neurol. 1972: 26; 465.

64. Kokmen E, Bossemeyer RW, Williams WJ. Neurological manifestations of aging. J Geronotol . 1978: 33; 62.

65. Laidlaw RW, Hamilton MA. A study of thresholds in perception of passive movement among normal control subjects. Bull Neurol Inst. 1937: 6; 268-340.

66. Skinner HB, Barrack RL, Cook SD. Age related decline in proprioception. Clin Orthop Rel Res. 1984:184; 208 - 211.

67. Smith E, Serfass R. Exercise and Aging: The Scientific Basis. Hillside, NJ: Enslow Publishers; 1981.

68. Turk MA, Geremski CA, Rosenbaum PF. Secondary Conditions of Adults with Cerebral Palsy: Final Report. Syracuse, NY.: State University of New York, Health Science Center at Syracuse, Department of Physical Medicine and Rehabilitation; 1997.

69. Wagner ML. Pharmacotherapy of seizures. Paper presented at the College of Pharmacy, Rutgers - The State University of New Jersey; 1993.

70. King W, Levin R, Schmidt R, Oestreich A, Heubi J. Prevalence of reduced bone mass in children and adults with spastic quadriplegic Dev Med Child Neurol 2003; 45: 12 - 16.

71. Center J, Beange $\mathrm{H}$, McElduff A. People with mental retardation have an increased prevalence of osteoporosis: A population study. Am J Mental Retard. 1998: 103; 19-28.

72. Kumar V, Cotran RS, Robbins SL. Basic Pathology. Philadelphia, PA: W.B. Saunders Company; 1992; 693 - 695.

73. Cathels BA, Reddihough DS. The health care of young adults with cerebral palsy. Med J Aust.1993; 159: 444-446.

74. Walz T, Harper D, Wilson J. The aging developmental disabled person : A review. The Gerontologist. 1986:26; 622 - 629 .

75. Bassey EJ, Harries UJ. Normal values for handgrip strength in 920 men and women aged over 65 years, and longitudinal changes over 4 years in 620 survivors. Clin Science 1993: 84; 331- 337.

76. Christ CB, Boilean RA, Slaughter MH, Stillman RJ, et al.. Maximal voluntary isometric force production characteristics of six muscle groups in women aged 25 - 74 years. Am J Human Biol 1992: 4; 537-545.

77. Shephard RJ, Montelpare W, Plyley M, et. al. Handgrip dynamometry. Cybex measurements and lean mass as markers of the ageing of muscle function. Br J Sp Med 1991: 25; 204-208.

78. Bemben MG, Massey BC, Bemben DA, et al.. Isometric muscle force production as a function of age in healthy 20 - to 74-yrold men. Med Sci Sports Exerc 1991: 23; 1302 - 1310.

79. Lexell J, Henriksson-Larsen B, Windled B, et al. . Distribution of different fiber types in human skeletal muscle: Effects of aging studied in whole muscle cross sections. Muscle Nerve 1983: 6; 588 - 595 .
80. Murray P. Strength of isometric and isokinetic contractions in knee muscles of men aged 20 to 86. Phys Ther 1980: 60; 412419.

81. Turk MA, Geremski CA, Rosenbaum PF, et al.. The health status of women with cerebral palsy.Arch Phys Med Rehab 1997; 78: S10-17.

82. Janicki MP, Jacobson JW. Generational trends in sensory, physical, and behavioral abilities among older mentally retarded persons. AJMD 1986: 90; 490 - 500.

83. Andersson C,Grooten W, Hellsten M, et al. Adults with cerebral palsy: Walking ability after progressive strength training. Dev Med Child Neurol 2003; 45: 220 - 228.

84. Naylor A, Happy F, MacRae T. Changes in the human intervertebral disc with age: A biophysical study. J Am Geriatr Soc 1955: 3; 964-973.

85. White AA, Panjabi MM. Clinical Biomechanics of the Spine Philadelphia, PA: JB Lippincott; 1978.

86. Borenstein DG, Burton JR. Lumbar spine disease in the elderly. J Am Geriatr Soc 1993: 41; 167 - 175.

87. Tkaczuk H. Tensile properties of human lumbar longitudinal ligaments. Acta Orthop Scand Suppl 1968: 115; 54 - 56.

88. Nachemson AL, Evands JH. Biomechanical study of human lumbar ligamentum flavum. J Anat 1969: 105; 188 - 189.

89. Lewis CB. Musculoskeletal changes with age : Clinical implications. In Lewis CB (ed). Aging: The health care challenge. 3rd ed. Philadelphia, PA: FA Davis Co; 1996.

90. Kalen V, Conklin MM, Sherman FC. Untreated scoliosis in severe cerebral palsy. J Pediatr Orthop 1992; 12: 337 - 340.

91. Majd ME, Muldowny DS, Holt RT. Natural history of scoliosis in the institutionalized adult cerebral palsy population. Spine 1997; 22: 1461-1466.

92. Thometz JG, Simon SR. Progression of scoliosis after skeletal maturity in institutionalized adults who have cerebral palsy. J Bone Joint Surg Am 1988; 70: 1290 - 1296.

93. Hauser WA, Hesdorffer DC. Epilepsy: Frequency, causes and consequences. New York, NY: Demos; 1990.

94. Stein RE, Stelling FH. Stress fracture of the calcaneous in a child with cerebral palsy. J Bone Joint Surg 1977; 59-A: 131.

95. McIvor WC, Samilson RL. Fractures in patients with cerebral palsy. J Bone Joint Surg 1966; 48-A: 858-866.

96. Brunner R, Doderlein L. Pathological fractures in patients with cerebral palsy. J Pediatri Orthop Part B 1996; 5: 232-238.

97. Imms F, Edholm F. The assessment of gait and mobility in the elderly. Age and Aging 1979: 8; 261.

98. Schenkman M: Interrelationship of neurological and mechanical factors in balance control. In Duncan PW ( ed). Balance: Proceedings of the American Physical Therapy Association Forum. Alexandria, VA: APTA Publications; 1990.

99. Woollacott MH. Changes in posture and voluntary control in the elderly: Research findings and rehabilitation. Top Geriatr Rehabil $1990: 5 ; 1-11$.

100.Mankovskii N, Mints YA, Lysenyuk UP. Regulation of the preparatory period of complex voluntary movement in old and extreme old age. Human Physiol 1980: 6; 46 - 50. 
101. Woollacott H, Shumway-Cook A, Nashner L. Aging and posture control: Changes in sensory organs and muscular coordination. Int J Aging Hum Dev 1986: 23; 97-114.

102.Adlin M. Health care issues. In Sutton E, Factor AR, Hawkins, Heller T, Seltzer GB (eds). Older adults with developmental disabilities: Optimizing choice and change. Baltimore, MD: Paul H. Brookes Publishing Co; 1993.

103.Pimm P. Cerebral palsy: “ A non-progressive disorder”? Education and Child Psychology 1992: 9; 27-33.

104.Turk MA, Machember RH. Cerebral palsy in adults who are older. In Machember RH, Overeynder (eds). Understanding aging and developmental disabilities: An in-service curriculum. Rochester, NY: University of Rochester; 1993.

105.Eman RK, Borthwick-Duffy SA. Trends in mortality rates and predictors of mortality. In Seltzer MM, Krauss MW, Janicki MP (eds). Life Course Perspectives on Adulthood and Old Age. Washington, DC: American Association on Mental Retardation; 1994.

106.Strauss D, Kastner TA. Comparative mortality of people with mental retardation in institutions and the community. AJMD 1996:101; 26 - 40.

107.Mittman C, Edelman NH, Norris AH, Shock NW. Relationship between chest wall and pulmonary compliance and age. J Appl Physiol 1965:10; 1211 - 1216.

108.Wright RR. Elastic tissue of normal and emphysematous lungs: A tridimensional histologic study. Am J Pathol 1961: 30; 355 $-367$.

109.Turner JM. Mead J, Wohl ME. Elasticity of human lungs in relation to age. J Appl Physiol 1968: 25; 664 -671.

110.John R, Thomas J. Chemical compositions of elastins isolated from aortas and pulmonary tissues of humans of different ages. Biochem J 1972:127; 261.

111.Pump KK. Fenestrae in the alveolar membrane of the human lung. Chest 1974: 65; $431-436$.

112.Smith E, Serfass R (eds). Exercise and Aging: The Scientific Basis. Hillside, NJ: Enslow; 1981.
113.Hernandez JA, Anderson AE, Holmes WL, Foraker AG. The bronchial glands in aging. J Am Geriatr Soc 1965:13; 799 - 803.

114.Shephard RT. Physical Activity and Aging. Rockville, MD: Aspen Publications; 1987, pp. 16-29,97.

115. National Health Interview Survey, 1988. Vital and Health Statistics Series 10, No 173. Washington, DC: Public Health Service, DHHA Publication No (PHS) 89 - 1501; 1989.

116.Compton DM, Eisenman PA, Henderson HL. Exercise and fitness for persons with disabilities. Sports Medicine 1989:7; 150 -162 .

117.Pitetti KH, Tan DM. Effects of a minimally supervised exercise program for mentally retarded adults. Medicine and Science in Sports and Exercise 1991:23; 594- 601.

118.Rimmer JH. Exercise and physical activity in persons aging with a physical disability. Phys Med Rehabil Clin N Am 2005; 16; $41-56$.

119.Ferrang TM, Johnson RK, Ferrara MS. Dietary and anthropometric assessment of adults with cerebral palsy. Journal of the American Dietary Association 1992: 92; 1083 - 1086.

120.Overeynder JC, Turk MA. Cerebral palsy and aging: a framework for promoting the health of older persons with cerebral palsy. Top Geriatr Rehabil 1998; 13: 19 - 24.

121.Thase ME. Longevity and mortality in Down's Syndrome. J of Mental Defic Res 1982: 27; 133-142.

122.Dalton AJ, Crapper DR. Down's syndrome and aging of the brain. In: Mittler P, (ed). Research to practice in mental retardation: Biomedical aspects, Vol. III. Baltimore, MD: University Park Press, 1977.

123.Fenner ME, Hewitt KE, Torpy DM. Down's syndrome: Intellectual and behavioral functioning during adulthood. J of Ment Defic Res 1987; 31: 241 - 249.

124.Hewitt KE, Jancar J. Psychological and clinical aspects of aging in Down's syndrome. In: Berg JM ( ed). Science and Service in mental retardation. London, England: Methuen, 1986: 370-379. 